\title{
Polyamines Upregulate Cephalosporin C Production and Expression of $\beta$-Lactam Biosynthetic Genes in High-Yielding Acremonium chrysogenum Strain
}

\author{
Alexander A. Zhgun * and Mikhail A. Eldarov *, \\ Group of Fungal Genetic Engineering, Federal Research Center "Fundamentals of Biotechnology" of the Russian \\ Academy of Sciences, 119071 Moscow, Russia \\ * Correspondence: zzhgun@mail.ru (A.A.Z.); eldarov1@yandex.ru (M.A.E.); Tel.: +7-916-9749769 (A.A.Z.) \\ + Deceased.
}

check for

updates

Citation: Zhgun, A.A.; Eldarov, M.A. Polyamines Upregulate Cephalosporin C Production and Expression of $\beta$-Lactam Biosynthetic Genes in High-Yielding Acremonium chrysogenum Strain. Molecules 2021, 26, 6636. https://doi.org/10.3390/ molecules 26216636

Academic Editors: Jean-Marc Sabatier and Soumaya Kouidhi

Received: 15 October 2021

Accepted: 30 October 2021

Published: 2 November 2021

Publisher's Note: MDPI stays neutral with regard to jurisdictional claims in published maps and institutional affiliations.

Copyright: (c) 2021 by the authors. Licensee MDPI, Basel, Switzerland. This article is an open access article distributed under the terms and conditions of the Creative Commons Attribution (CC BY) license (https:// creativecommons.org/licenses/by/ $4.0 /)$.
Abstract: The high-yielding production of pharmaceutically significant secondary metabolites in filamentous fungi is obtained by random mutagenesis; such changes may be associated with shifts in the metabolism of polyamines. We have previously shown that, in the Acremonium chrysogenum cephalosporin $\mathrm{C}$ high-yielding strain (HY), the content of endogenous polyamines increased by fourto five-fold. Other studies have shown that the addition of exogenous polyamines can increase the production of target secondary metabolites in highly active fungal producers, in particular, increase the biosynthesis of $\beta$-lactams in the Penicillium chrysogenum Wis 54-1255 strain, an improved producer of penicillin G. In the current study, we demonstrate that the introduction of exogenous polyamines, such as spermidine or 1,3-diaminopropane, to A. chrysogenum wild-type (WT) and HY strains, leads to an increase in colony germination and morphological changes in a complete agar medium. The addition of $5 \mathrm{mM}$ polyamines during fermentation increases the production of cephalosporin $\mathrm{C}$ in the A. chrysogenum HY strain by $15-20 \%$ and upregulates genes belonging to the beta-lactam biosynthetic cluster. The data obtained indicate the intersection of the metabolisms of polyamines and beta-lactams in A. chrysogenum and are important for the construction of improved producers of secondary metabolites in filamentous fungi.

Keywords: polyamines; filamentous fungi; biosynthesis of secondary metabolites; Acremonium chrysogenum; cephalosporin C

\section{Introduction}

Filamentous fungi (also called molds or moldy fungi) are taxonomically diverse organisms from phylum Ascomycota and Zygomycota with filamentous hyphae and the ability to produce airborne spores or conidia. Improved strains of filamentous fungi are one of the most important sources for producing pharmaceutically significant secondary metabolites (SMs), such as antibiotics, statins, and immunosuppressants [1-4]. These compounds are one of the most commonly prescribed drugs worldwide [5,6]. Acremonium chrysogenum-improved strains are the main source for obtaining cephalosporin C (CPC), the parent substance for producing antibiotics of the cephalosporin series of generations 1-5 [7-10].

A. chrysogenum HY (RNCM 408D) strain, the high-yielding CPC producer, was obtained as a result of multi-round random mutagenesis of an A. chrysogenum WT (ATCC 11550) [11]. This improved strain typically produces $9-12 \mathrm{~g} / \mathrm{L}$ of CPC during laboratory fermentation in shake flasks, 200-300 times higher than A. chrysogenum WT. The HY strain is one of the most comprehensively characterized among the improved $A$. chrysogenum producers of CPC $[2,11]$. For this strain, the chromosomal rearrangements compared to WT strain were shown; the number of copies and localization of biosynthetic gene clusters (BGCs) of betalactams, the so-called "early" and "late" clusters, were determined [12]. The expression of BGCs genes was measured; "early" and "late" were upregulated 5-300-fold [13]. The 
A. chrysogenum $\mathrm{HY}$ was one of the first highly active producers of SM in filamentous fungi, for which a genetic transformation using Agrobacterium tumefaciens-mediated transformation (ATMT) was developed [14]. Using this technology, we obtained a series of recombinant strains, expressing CefT (MFS beta-lactam transporter from A. chrysogenum) and PMA1 $\left(\mathrm{H}^{+}\right.$-ATPase the plasma membrane from S. cerevisiae), which made it possible to study in detail the features of transport and energy consumption of beta-lactam biosynthesis in A. chrysogenum [2,15]. The HY strain was also characterized by a shift in several biochemical parameters, particularly the content of five fractions of energy-rich inorganic polyphosphates (polyPs), ATP, and $\mathrm{H}^{+}$-ATPase activity in the plasma membrane [16]. Several morphological alterations in cell wall structure [17], in size of filamentous hyphae and conidia formation [14], and in colony size and coloration [15] were also demonstrated.

Recently, for this strain, significant changes in the metabolism of polyamines (PAs) were found, in particular, increased resistance to inhibitors of ornithine decarboxylase (ODC; EC 4.1.1.17), an enzyme of the key stage of PAs biosynthesis [18]. Additionally, the content of major PAs in HY cells during fermentation was increased (the content of spermidine was increased 5.2-fold; spermine was increased 4.5-fold) [18].

There are numerous known functions of PAs in fungi, associated with stress resistance [19], morphogenesis and differentiation of fungal cells [20-22], plant pathogenesis $[23,24]$, and many others $[25,26]$. In the last decade, it was shown that the introduction of exogenous PAs during the fermentation of improved SM-producing filamentous fungi could lead to an additional increase in the production of target SM [27,28]. This effect can be mediated by the work of LaeA, the key global regulator of SMs, which interacts with other components of the velvet complex (VeA, VelB, VelC, and VosA) [29-31]. It is so named because four of these proteins, VeA, VelB, VelC, and VosA, have an approximately 150-amino-acid domain called the velvet domain [32]. The velvet domain is a DNA-binding motif that specifically recognizes an 11-nucleotide consensus sequence consisting of two motifs in the promoters of key regulatory genes for fungal development; this domain is also involved in homo- or heterodimer formation [33,34]. These proteins form dimers, heterodimers, and heterotrimeric complexes with other proteins also involved in the regulation of morphogenesis, as well as metabolism and other cellular functions, in response to environmental stimuli, such as light or carbon source [35]. The heterotrimeric velvet complex proteins, LaeA/VeA/VelB, have been most studied in fungi to clarify the relation between light-dependent morphology and secondary metabolism [36]. There are a number of models for the functioning of the velvet complex [34,37]. One of the most important roles of this complex is associated with the global regulation of the secondary metabolism of fungi [38-40].

In this regard, the main goal of our work was to find and characterize, at the molecular level, the conditions under which the introduction of exogenous PAs can increase the yield of CPC in an improved A. chrysogenum HY strain.

\section{Results}

\subsection{Effect of PAs on A. chrysogenum Strains on an Agarized Medium}

\subsubsection{Growth of A. chrysogenum WT and HY Strains on an Agarized Complex Medium}

The high-yielding $A$. chrysogenum strain, during the multiround random mutagenesis to improve CPC production, became significantly less viable than the original wild-type strain; in particular, it lost the ability to form conidia [14]. It is also extremely sensitive to freezing at $-80^{\circ} \mathrm{C}$ (with standard cryoprotectants), lyophilization, and long-term storage at $4{ }^{\circ} \mathrm{C}$ on agarized media. A. chrysogenum $\mathrm{HY}$ cells die after such manipulations. The only stable method of maintaining this strain is sequential subculture on agarized media. However, with this method of storing the culture over time (after 3-4 transfers), low-active clones are released, which significantly reduces the yield of the strain. Such a splitting into low activity and high activity in the production of CPC clones may be due to epigenetic events, since the BGCs' loci are under the control of factors of global regulation, remodeling chromatin in these regions [41,42]. To maintain a highly active line, it is necessary to 
conduct periodic monospore sieving on an agarized medium, stimulating the formation of CPC, such as an agarized complex (CPA) medium. This leads to the identification of heterogeneity in the size of the colonies. There are relatively large colonies (low in the production of $\mathrm{CPC}$ ), medium-sized colonies, about two times smaller (actively producing CPC), as well as small colonies, 5-10 times smaller, with extremely low viability and unsuitable for effective CPC production (Figure 1). At the same time, the largest colonies of $A$. chrysogenum HY are significantly smaller in size (10-fold or more) than colonies in A. chrysogenum WT after monospore seeding on CPA medium (Figure 1). Additionally, the wild-type strain does not show heterogeneity in colony size on this medium.

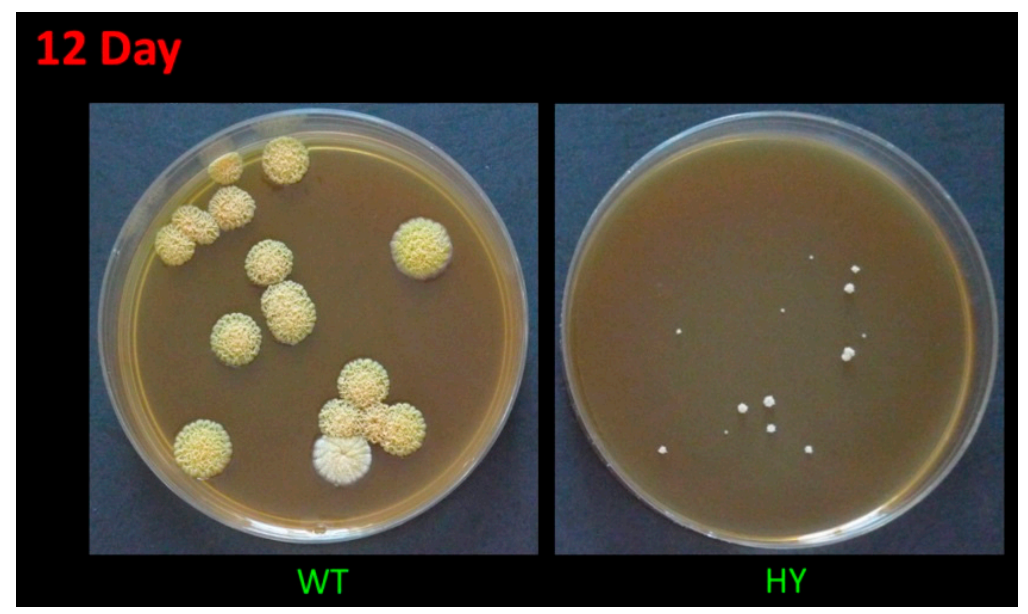

Figure 1. Growth of A. chrysogenum wild-type (WT) and high-yielding (HY) strains after 12 days on agarized complex (CPA) medium.

\subsubsection{Effect of PAs on the Coloration of A. chrysogenum Strains on a CPA Medium}

Colonies of A. chrysogenum WT have a characteristic yellow-cream color, which develops after 5-10 days, depending on the cultivation conditions on the agar nutrient medium, and due to the biosynthesis of the SM sorbicillin [43]. Single colonies can remain white for up to 12-15 days, but they also acquire a yellow-cream color (Figure 1).

In the current study, the addition of $5 \mathrm{mM}$ 1,3-diaminopropane (1,3-DAP) or $5 \mathrm{mM}$ spermidine (SPD) led to an earlier appearance of pigment coloration. After 4-5 days of inoculation, colonies grown on the medium supplemented with PAs were completely yellow, while most colonies on the control medium were white or just starting to turn yellow (Figure 2). After 10-15 days, the control strains completely stained yellow and did not differ in color (including its intensity) from cells grown on a medium containing PAs.

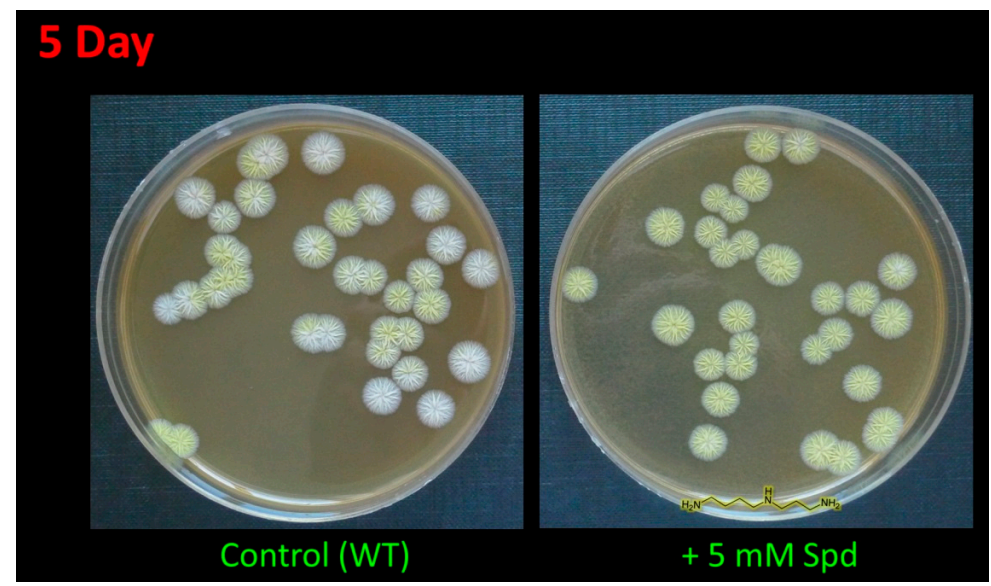

Figure 2. Effect of spermidine (SPD) on pigmentation of A. chrysogenum wild type (WT) strain. After 5 days on agarized complex (CPA) medium with the addition of $5 \mathrm{mM}$ Spd or without addition (control). 
The A. chrysogenum HY strain lost color pigmentation during the strain improvement (Figure 2) [14]. The addition of PAs to A. chrysogenum HY did not change the colony color; they remained white.

\subsubsection{Effect of PAs on Germination and Size of A. chrysogenum Colonies on CPA Medium}

To determine the effect of PAs on the germination and the size of the diameter of A. chrysogenum colonies on the CPA medium, 1,3-DAP and SPD were used in the concentration range of $0.1-10 \mathrm{mM}$.

For the WT strain, there were no significant changes in the number of germinated colonies and the size of their diameter upon addition of PAs in the range of $0.1-0.5 \mathrm{mM}$ (Figure 3a,c). The addition of $1 \mathrm{mM}$ 1,3-DAP resulted in a small (by 10-15\%) increase in the number of CFU/mL; the addition of $1 \mathrm{mM}$ SPD had no significant effect. The addition of $5 \mathrm{mM} 1,3-\mathrm{DAP}$ increased CFU/ $\mathrm{ml}$ by 25-30\%; the addition of $5 \mathrm{mM}$ SPD increased this parameter by $15-20 \%$.

A total of 0.1-5 mM PAs had no significant effect on the colony size of the A. chrysogenum WT strain. Small decreases in both growth parameters were observed upon the addition of $10 \mathrm{mM}$ PAs, which may indicate the toxicity of these compounds at such concentrations (Figure 3a,c). Previously, using Saccharomyces cerevisiae as a model object, we demonstrated that high concentrations of PAs can be toxic to fungal cells [15]. For this, we studied (i) a series of $S$. cerevisiae strains from the Euroscarf collection, with knockouts for various MDR (multidrug resistance) transporters (BY4741 $\Delta y b r 043 c(\Delta Q d r 3), B Y 4741$ $\Delta y p r 156 \mathrm{c}(\Delta \mathrm{Tpo} 3)$, and BY4741 $\Delta y 11028 \mathrm{w}(\Delta \mathrm{Tpo} 1)$ and (ii) based on them recombinant analogs, heterologously expressing cefT gene for the MDR transporter from A. chrysogenum. The functioning of the CefT transporter in recombinant clones made it possible to more effectively resist the toxic effect caused by the addition of high concentrations of SPD for yeast cells as compared to the control [15]. This shows that PAs in high concentrations are toxic to fungi; the threshold of resistance to toxic concentrations of exogenous PAs can be significantly different for different strains.

We found that adding the studied PAs to the CPA medium could significantly affect germination and colony size of $A$. chrysogenum $\mathrm{HY}$ strain (Figure $3 \mathrm{~b}, \mathrm{~d}, \mathrm{e}$ ). The stimulation of germination of colonies and an increase in their size began at concentrations of $0.5 \mathrm{mM}$ and reached the strongest effect at $5 \mathrm{mM}$.

The addition of $0.5 \mathrm{mM} 1,3-\mathrm{DAP}$ or SPD increased the number of germinating colonies by $\sim 1.5$-fold; $1 \mathrm{mM}$ of these compounds increased CFU / $\mathrm{ml}$ by $\sim$ two-fold. At the 5-mM concentration, PAs had a different degree of stimulating effect. Five mM SPD increased approximately $\sim 3.5$-fold CFU/ $\mathrm{ml}$ compared to the control; $5 \mathrm{mM}$ 1,3-DAP stimulated this even more - the increase was $\sim$ five-fold. The addition of $0.1-0.25 \mathrm{mM}$ PAs had no effect. A $10 \mathrm{mM}$ concentration of 1,3-DAP or SPD was toxic. The number of germinated colonies decreased by $20 \%$ with $10 \mathrm{mM}$ 1,3-DAP and even more, by $25 \%$, with the addition of $10 \mathrm{mM}$ SPD.

The PAs addition also led to a change in the phenotype of the colony size of the HY strain on the CPA medium (Figure 3e). The addition of 1,3-DAP in the concentration range of $0.5-5 \mathrm{mM}$ led to a gradual disappearance of heterogeneity in the colony size due to the increase in small and medium colonies to the size of large colonies. The maximum effect of adding $5 \mathrm{mM}$ 1,3-DAP led all colonies of the HY strain to become the same size, corresponding to the size of the large control colonies; as a result, the total average diameter of the colonies increased $\sim$ two-fold to the control (Figure $3 \mathrm{~d}$ ). The addition of $0.1-0.25 \mathrm{mM}$ 1,3-DAP did not affect the colony size; $10 \mathrm{mM}$ 1,3-DAP resulted in a sharp decrease in colony size compared to $5 \mathrm{mM}$ 1,3-DAP, which may indicate the toxicity of such a high concentration of this substance.

The addition of SPD caused similar effects of 1,3-DAP: $0.1-0.25 \mathrm{mM}$ concentration had no significant effect, $0.5-5 \mathrm{mM}$ was stimulated with the greatest effect at $5 \mathrm{mM}$, and $10 \mathrm{mM}$ was toxic to cells. While the general trend was similar, SPD had a significantly more pronounced stimulating effect on increased colony size than 1,3-DAP. Thus, the addition of $5 \mathrm{mM}$ SPD resulted in a significant change in the macromorphology of $\mathrm{HY}$ 
strain colonies. They became twice as large in colony diameter as the largest colonies on the control medium; moreover, they were all the same size (Figure 3d,e).

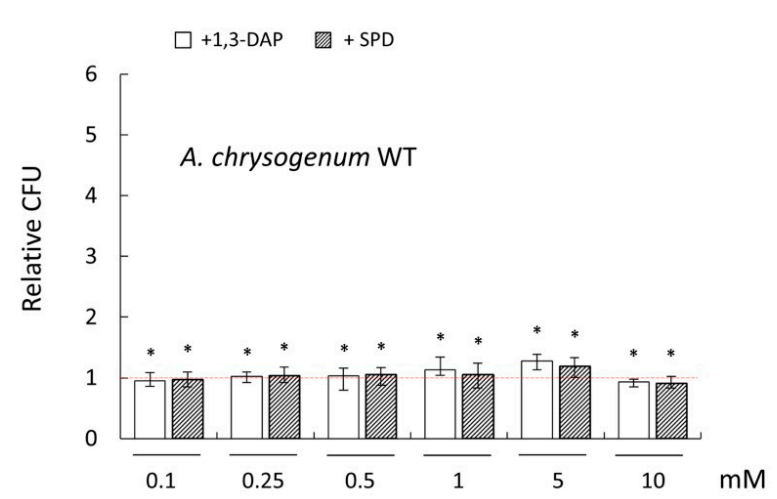

(a)

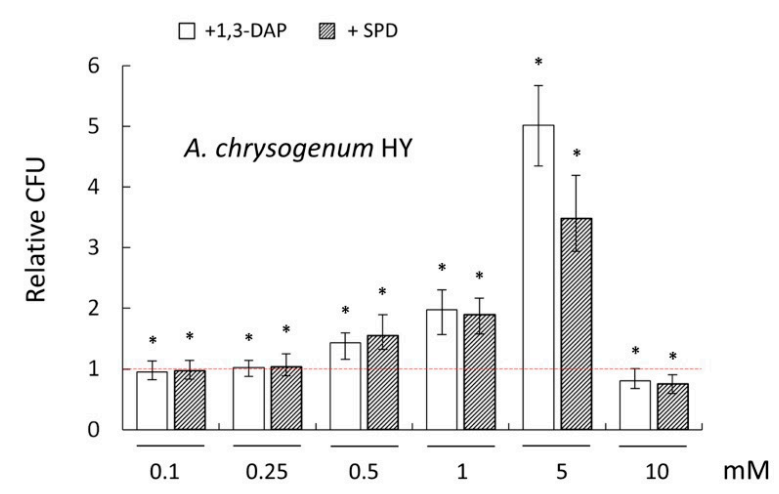

(b)

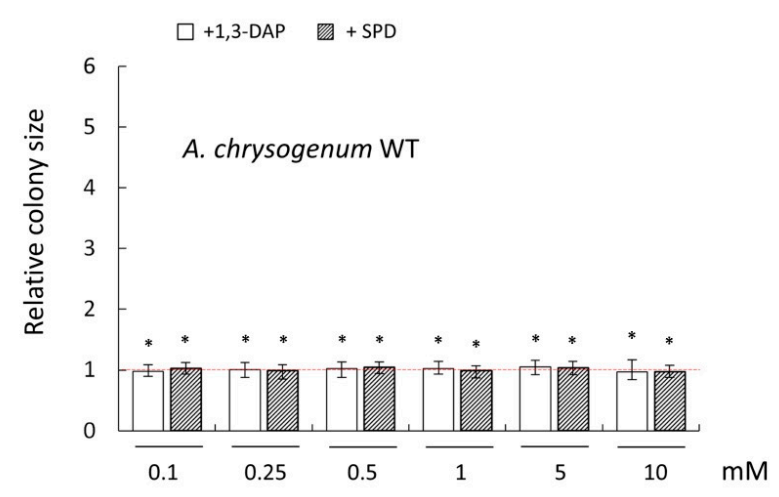

(c)

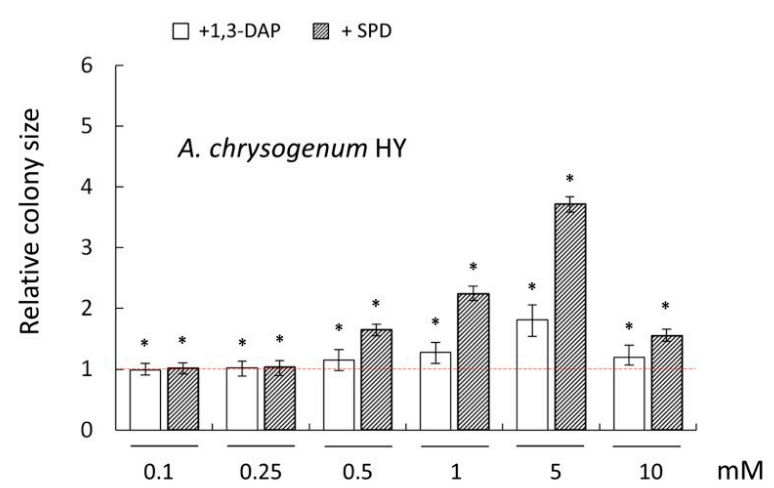

(d)

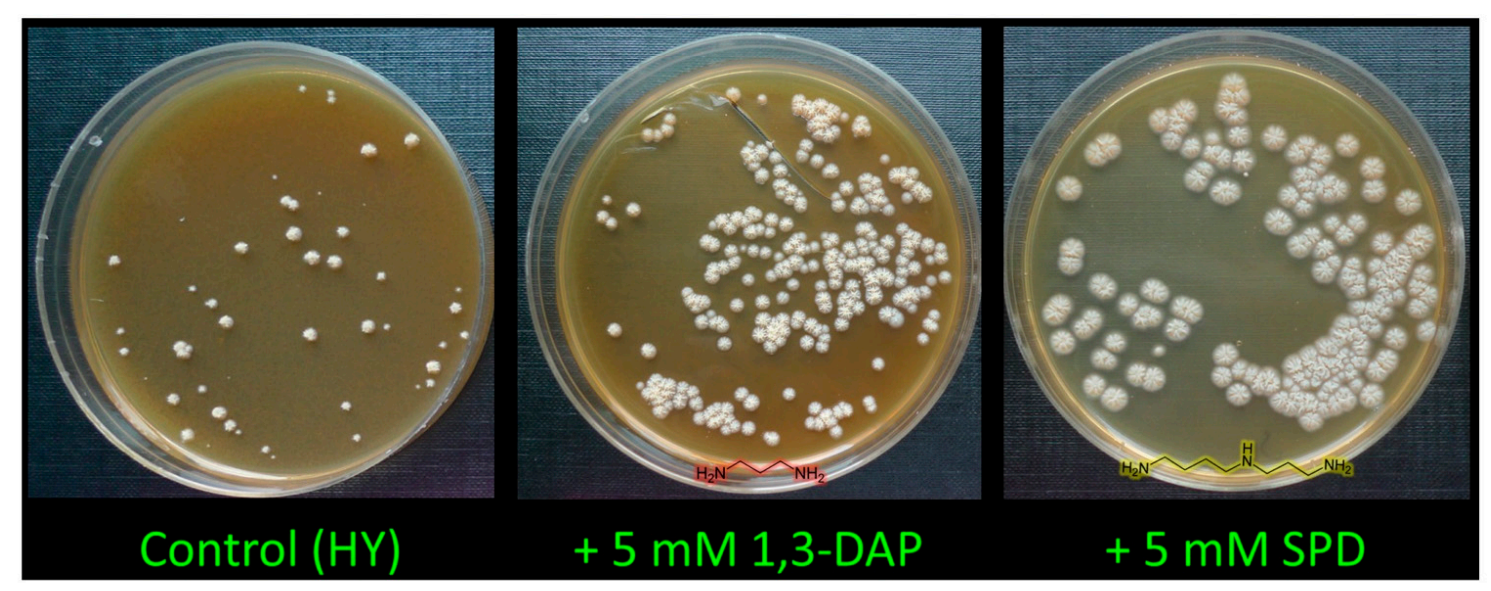

(e)

Figure 3. Effect of 1,3-diaminopropane (1,3-DAP) and spermidine (SPD) on the number and diameter size of germinating colonies of $A$. chrysogenum strains on agarized complex (CPA) medium: (a,c) A. chrysogenum wild type (WT) strain; (b,d,e) A. chrysogenum high-yielding (HY) strain. (a,b) Relative CFU (colony forming units) - the ratio of the of cell counts after incubation on CPA medium with PAs compared control counts (on CPA medium without any additions). (c,d) Relative size-the ratio of the average diameter of all colonies after inoculation on CPA with PAs compared to control's average diameter of colonies (on CPA media without any additions). Dotted lines show the relative CFU level or colony diameter for strains inoculated on CPA without additives. Data are means $\pm \mathrm{SD}, n=3$. Statistical significance, ${ }^{*} p \leq 0.05$, as compared with the control (strain, cultivated on medium without PAs additions). (e) 12 days after inoculation of A. chrysogenum $\mathrm{HY}$ strain on CPA medium with the addition of $5 \mathrm{mM}$ 1,3-DAP or $5 \mathrm{mM} \mathrm{Spd,} \mathrm{or} \mathrm{without} \mathrm{addition} \mathrm{(control).}$ 


\subsection{Submerged Fermentation of A. chrysogenum HY Strain with Exogenous PAs}

2.2.1. Optimization of Cultivation A. chrysogenum HY Strain with PA to Increase CPC Production

At the first stage, our experiments showed that the addition of exogenous PAs could significantly affect the viability and morphology of A. chrysogenum $\mathrm{HY}$ on the CPA medium, expressed in an increase in $\mathrm{CFU} / \mathrm{mL}$ and colony size. In this regard, our further task was to find out whether exposure from exogenous PAs can also lead to an additional increase in the production of CPC.

The studied A. chrysogenum HY strain was improved for the overproduction of CPC during submerged fermentation [11]. It is known that phenotypic effects obtained on agar medium do not always scale [44]. Additionally, fungal strains improved for solid-state fermentation (SSF), and submerged fermentation most efficiently produced the target SM in the environment for which the improvement was made [45]. This is due to both the difference in regulation during SSF and submerged fermentation and many other reasons affecting the biosynthesis of the target SM [46,47]. Therefore, we took the data obtained from the phenotypic responses of $A$. chrysogenum HY to add PAs on the agar medium only as a starting point for optimizing the submerged fermentation. There, we used the concentration of PAs in the range of $0.5-5 \mathrm{mM}$ (since on agar media, concentrations of 0.1-0.25 mM turned out to be ineffective, and the concentration of $10 \mathrm{mM}$ was toxic). In addition to testing different concentrations of PAs, we varied the time of their introduction at the preliminary stages and during the biosynthesis of CPC (Figure 4).

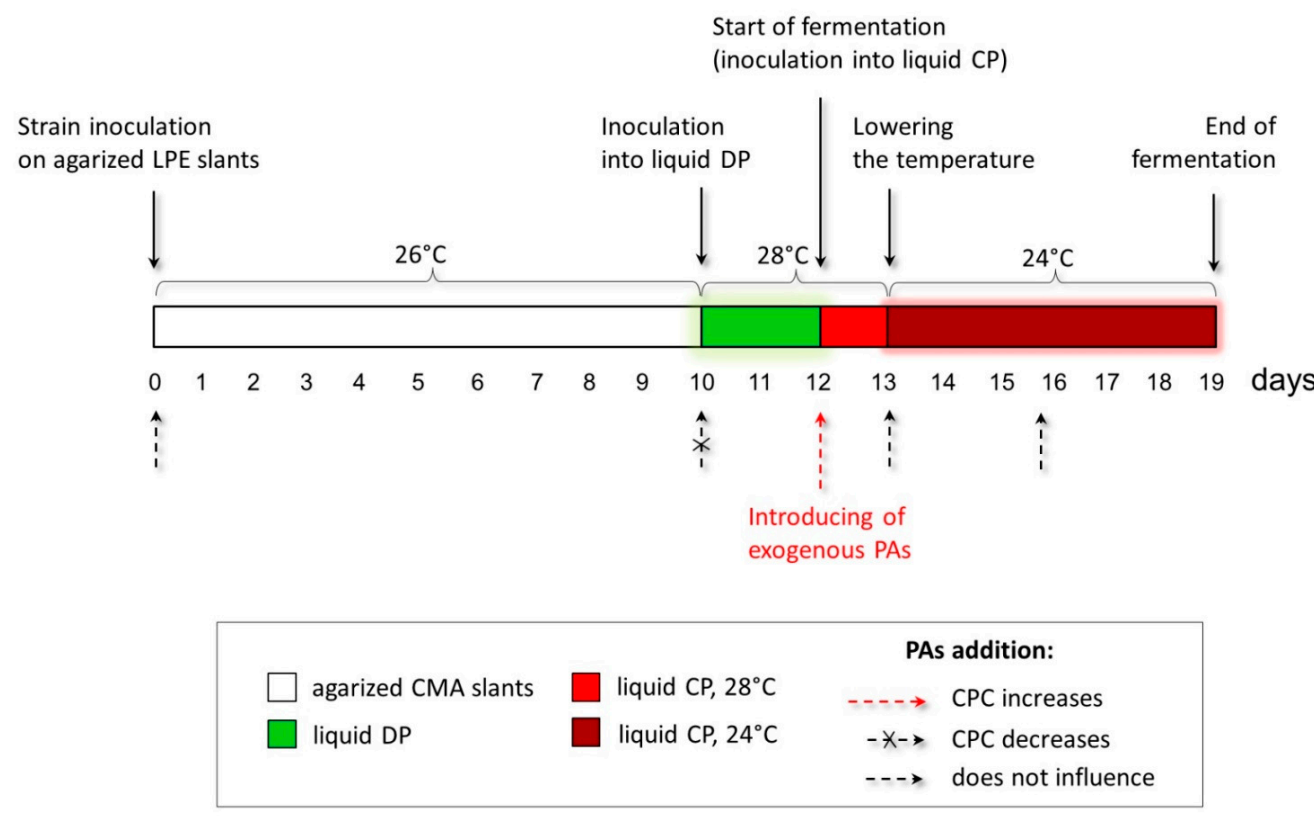

Figure 4. Optimization of the conditions for introducing exogenous polyamines (PAs) to increase cephalosporine C (CPC) production in the A. chrysogenum high-yielding (HY) strain. The red dashed arrow shows the optimal time for PAs' addition to increase CPC production at the inoculation from liquid defined (DP) medium to liquid complex (CP) medium. Small dashed arrows mark the periods of strain cultivation when the addition of PAs does not affect CPC production. The small crossed-out dashed arrow marks the period when the addition of PAs leads to a decrease in CPC production.

The process of obtaining CPC from A. chrysogenum includes several sequential steps associated with obtaining an inoculum on an enriched agar medium, preliminary cultivation on a liquid defined (DP) medium, and growing in a liquid complex (CP) medium with a decrease in temperature after the first $24 \mathrm{~h}$ of incubation (Figure 4). We investigated the impact of adding PAs at each stage. In most cases, adding 0.5-5 mM 1,3-DAP or SPD did not result in significant shifts in dry biomass and CPC production. 
It turned out that the optimal for increasing production is the introduction of $5 \mathrm{mM} 1,3-$ DAP or $5 \mathrm{mM}$ SPD directly into the CP medium at the time of transfer of the accumulated culture on the DP medium (Figure 4). The increase in the production of CPC is not affected by preliminary cultivation on LPE slants with the addition of PAs. Additionally, there were no differences if the cell culture was carried out through two consecutive passages on a slant agar supplemented with PAs. An increase in CPC production does not occur when exogenous PAs are added to the $\mathrm{CP}$ medium after $24 \mathrm{~h}$ or at later stages of fermentation. The additions of $5 \mathrm{mM}$ 1,3-DAP or SPD to the liquid DP medium significantly reduced both the yield of CPC and the weight of dry biomass. This concentration of PAs appears to be toxic when added to a low-nutrient DP medium. The addition of $0.5-1 \mathrm{mM}$ PAs had no significant effect on biomass growth and CPC production of the A. chrysogenum HY strain.

In this regard, for our further study of the effect of PAs on increasing the production of the target SM in the improved A. chrysogenum strain, we used $5 \mathrm{mM} 1,3-\mathrm{DAP}$ or $5 \mathrm{mM}$ SPD to be added at $0 \mathrm{~h}$ of fermentation, that is, at the time of transfer of the culture from the DP to the CP medium (corresponds to day 13 of work with the strain, according to Figure 4).

2.2.2. Effect of the Addition of $5 \mathrm{mM}$ PAs on CPC Production, Biomass, and Specific CPC Yield during Submerged Fermentation of A. chrysogenum HY

Determination of the most effective concentration and a suitable period for introducing exogenous PAs allowed, at the next stage of work, to study the dynamics of the stimulating effect on the production of CPC in A. chrysogenum HY (Figure 5a).

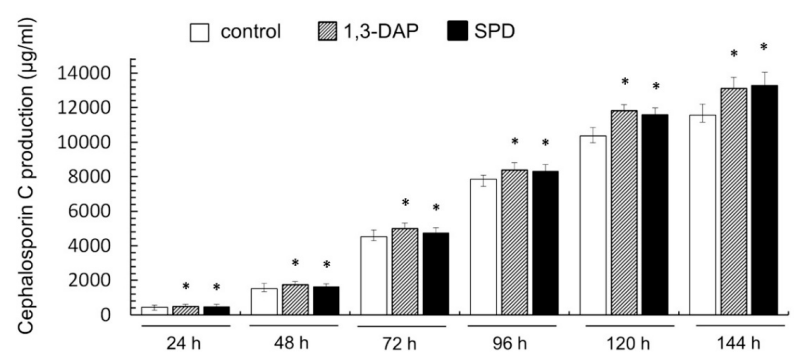

(a)

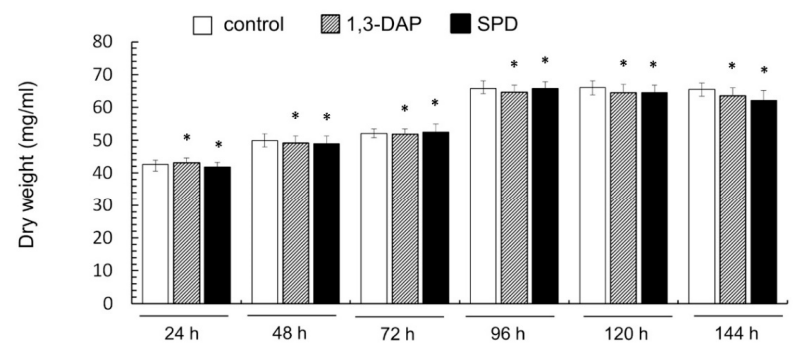

(b)

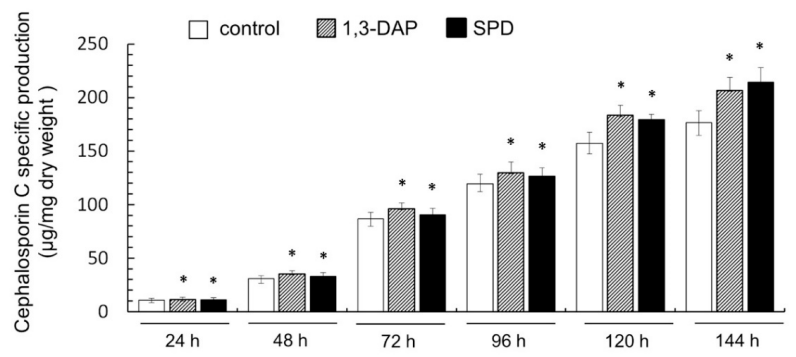

(c)

Figure 5. Effect of the addition of $5 \mathrm{mM}$ 1,3-DAP or $5 \mathrm{mM}$ spermidine (SPD) on cephalosporin C (CPC) production and growth of A. chrysogenum HY strain during fermentation on complex (CP) medium: (a) CPC production; (b) dry weight; (c) CPC specific production. Samples were taken at $24 \mathrm{~h}, 48 \mathrm{~h}, 72 \mathrm{~h}, 96 \mathrm{~h}, 120 \mathrm{~h}$, and $144 \mathrm{~h}$. Data are means $\pm \mathrm{SD}, n=3$. Statistical significance, ${ }^{*} p \leq 0.05$, as compared with the control (strain, cultivated on medium without PAs additions). 
Samples were analyzed every $24 \mathrm{~h}$ from the beginning of cultivation on the $\mathrm{CP}$ medium until the end of the process after $144 \mathrm{~h}$ (corresponds to 13-19 days of work with the strain, according to Figure 4). We also studied biomass accumulation during fermentation (Figure 5b), which allowed us to determine the specific yield of CPC per unit dry weight (Figure 5c).

It turned out that the addition of PAs did not have a significant effect on the production of CPC on the first day of fermentation (Figure 5c). Further, within 48-96 h, a small but distinct stimulating effect was observed. Cultivation in the presence of $5 \mathrm{mM} 1,3-\mathrm{DAP}$ increased CPC production by $7-14 \%$; the addition of $5 \mathrm{mM}$ SPD increased CPC production by $5-6 \%$. The stimulating effect of adding $5 \mathrm{mM}$ PAs was manifested in the late stage of fermentation. After 120-144 h of cultivation with $5 \mathrm{mM} 1,3-\mathrm{DAP}$, the production of CPC was $13-14 \%$ higher than in the control. The addition of SPD led to an increase in the yield of SPD by $11-12 \%$ after $120 \mathrm{~h}$ and up to $15 \%$ after $144 \mathrm{~h}$ (Figure 6). In absolute terms, after $144 \mathrm{~h}$, the HY strain on the SP medium without additive produced $11,500 \mathrm{mg} / \mathrm{L}$ of CPC; the SP medium supplemented with $5 \mathrm{mM}$ SPD produced $\sim 13,300 \mathrm{mg} / \mathrm{L}$ of CPC (Figures $5 \mathrm{c}$ and 6 ). At the same time, there was no increase in the relative level of beta-lactam biosynthesis byproducts such as deacetoxycephalosporin $\mathrm{C}$ (DAOC) or deacetylcephalosporin C (DAC), which was observed previously after some manipulations with this strain [2,15] (Figure 6).

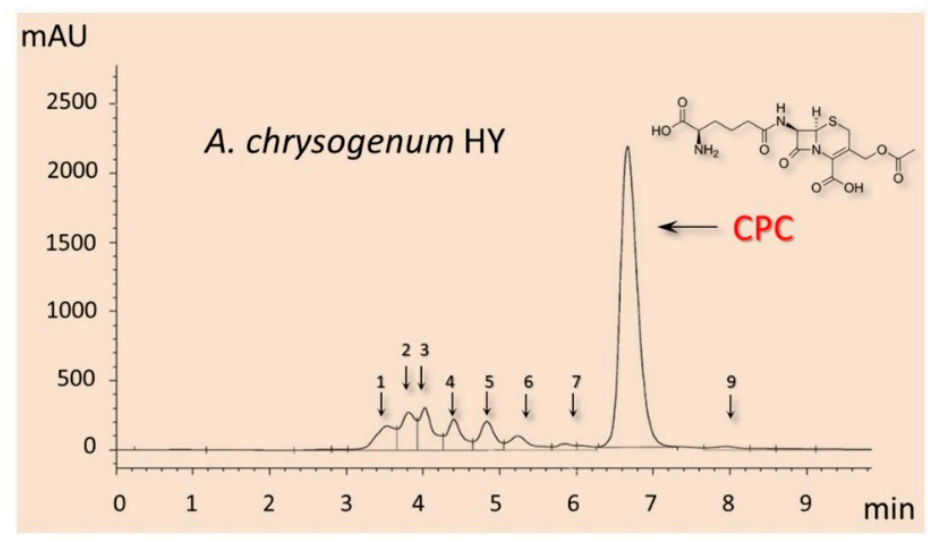

(a)

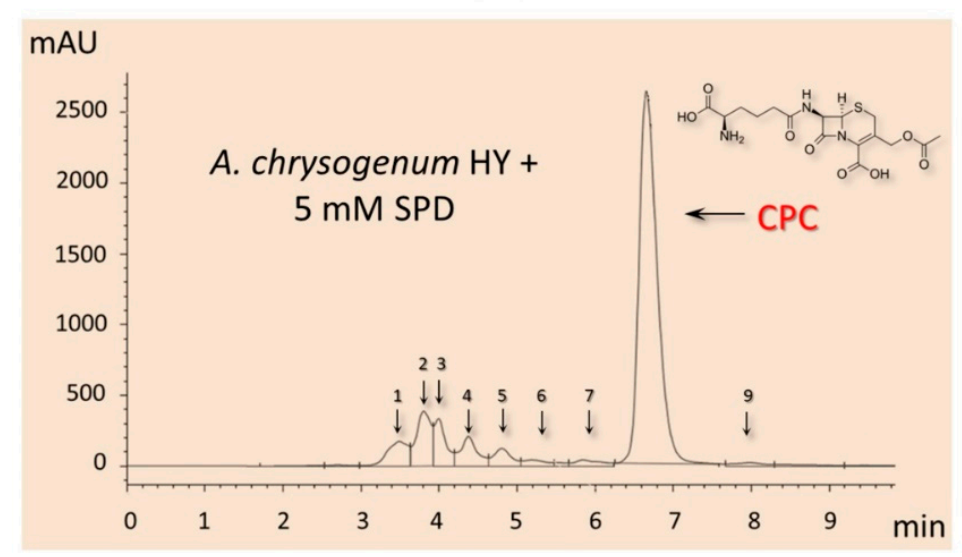

(b)

Figure 6. HPLC analysis of beta-lactam production of the A. chrysogenum high-yielding (HY) strain after $144 \mathrm{~h}$ of cultivation on complex (CP) medium: (a) cultivation without additives (control); (b) with $5 \mathrm{mM}$ spermidine (SPD) added at the starting point of cultivation.

The active growth of the biomass of the A. chrysogenum HY strain during cultivation on the $\mathrm{CP}$ medium without additives occurred for up to $96 \mathrm{~h}$; then, a stationary phase began. The amount of biomass practically did not change until the end of fermentation. (Figure 5b). The addition of PAs had no significant effect on biomass production until the 
final fermentation period, when a slight decrease was observed, up to $3 \%$, when cultured with $5 \mathrm{mM} 1,3-\mathrm{DAP}$ and up to $5 \%$ when cultured with $5 \mathrm{mM} \mathrm{SPD}$.

A slight decrease in the amount of biomass accompanying an increase in CPC production at the final stage of fermentation with PAs led to an even more significant increase in the specific CPC production, expressed in $\mu \mathrm{g} / \mathrm{mg}$ dry weight, compared to the control (Figure $5 \mathrm{c}$ ). The addition of $5 \mathrm{mM}$ DAP increased the specific production of CPC after $120-144 \mathrm{~h}$ by $16-17 \%$. The effect of adding $5 \mathrm{mM}$ SPD was even greater; after $120 \mathrm{~h}$, the specific production of CPC increased by $14 \%$; after $144 \mathrm{~h}$, the increase reached $20-21 \%$.

2.3. Analysis of the CPC Production and Expression Level of the Corresponding Biosynthetic Genes in the A. chrysogenum HY Strain after the Addition of Exogenous PAs during Fermentation

The study of the effect of PAs on the level of CPC biosynthesis during fermentation of A. chrysogenum $\mathrm{HY}$ strain made it possible to choose the optimal time of their introduction to increase the production of this SM. Since the maximum effect from the addition of PAs was found at the final stage of fermentation, to determine the molecular basis of such an increase in CPC production, the expression level of the "early" and "late" beta-lactam genes was measured, starting from $1 \mathrm{~h}$ after the transfer of the culture from the DP medium to the $\mathrm{CP}$ medium until the end of fermentation after $144 \mathrm{~h}$. Samples were collected every $24 \mathrm{~h}$.

We studied the expression of biosynthetic genes of the "early" beta-lactams BGC: (i) gene pcbAB for ACV ( $\delta$-[L- $\alpha$-Aminoadipyl]-L-Cysteinyl-D-Valine) synthetase (EC: 6.3.2.26), the central enzyme in the biosynthesis of beta-lactams, which creates in ACV tripeptide as NRPS (nonribosomal peptide synthetase); (ii) gene $\mathrm{pcbC}$ for isopenicillin $\mathrm{N}$-synthase (EC: 1.21.3.1), oxygenase, which synthesizes penicillin N (IPN) from the ACV tripeptide; (iii) gene cefD1 for isopenicillin N-CoA synthetase (EC: 5.1.1.17), IPN epimerase component 1 , which activates IPN by the acyl-CoA synthase; (iv) gene cefD2 for isopenicillin N-CoA epimerase (EC: 5.1.1.17), IPN epimerase component 2, which epimerizes IPN-CoA to penicillin N (PenN). We also studied the expression of biosynthetic genes of the "late" betalactams BGC: (v) gene cefEF for deacetoxycephalosporin C synthetase (penN expandase) (EC 1.14.20.1)/deacetoxycephalosporin C hydroxylase (1.14.11.26), which sequentially catalyzes two oxygenase reactions for the conversion of PenN to DAOC and then to DAC; (vi) gene cefG for deacetylcephalosporin-C acetyltransferase (EC 2.3.1.175), which transfers the acetyl residue from acetyl coenzyme A to the DAC to produce CPC.

A total of $1 \mathrm{~h}$ after the transfer of the culture from the DP medium to the $\mathrm{CP}$ medium with or without PAs no differences in the expression of genes for the biosynthesis of beta-lactams were observed (Figure 7).

Then, the dynamics of expression for "early" and "late" genes of beta-lactam biosynthesis differed. In control samples (collected from the CP medium without additives), the level of mRNA expressed from the "early" genes smoothly increased in the range of 24-96 $\mathrm{h}$, for $p c b A B$ and $p c b C$, or in the range of $24-120 \mathrm{~h}$, for $c e f D 1$ and cefD2; after a period of growth in gene expression, there was a slight drop in this level in all cases (Figure 7a-d). In the control for "late" genes, the expression level changed slightly, up to the middle of fermentation, $72 \mathrm{~h}$; and then a rapid increase in the level of expression began at 72-120 h. By the end of the fermentation, the expression level either increased slightly for cefEF or decreased for $c e f G$.

The addition of PAs in most cases either did not change the level of expression of both "early" and "late" genes (more often it manifested itself in the early stages of fermentation) or led to their upregulation (more often it manifested itself in the middle and end of fermentation). If upregulation for a certain gene occurred at a certain time point, then in most cases, it was caused by both polyamines; the upregulation with the addition of spermidine was generally slightly higher; it could reach 6-8-fold. In only a few cases, 1,3-DAP upregulated the studied genes more strongly than spermidine, for example, cefD 1 after $24 \mathrm{~h}$ or $\operatorname{cefG}$ after $144 \mathrm{~h}$. Among the biosynthetic genes of betalactams, cefG was most strongly upregulated in the period $72-144 \mathrm{~h}$; the addition of 1,3DAP upregulated cefG 2-4 times; the addition of spermidine upregulated cefG 3-8 times, compared with the control. 


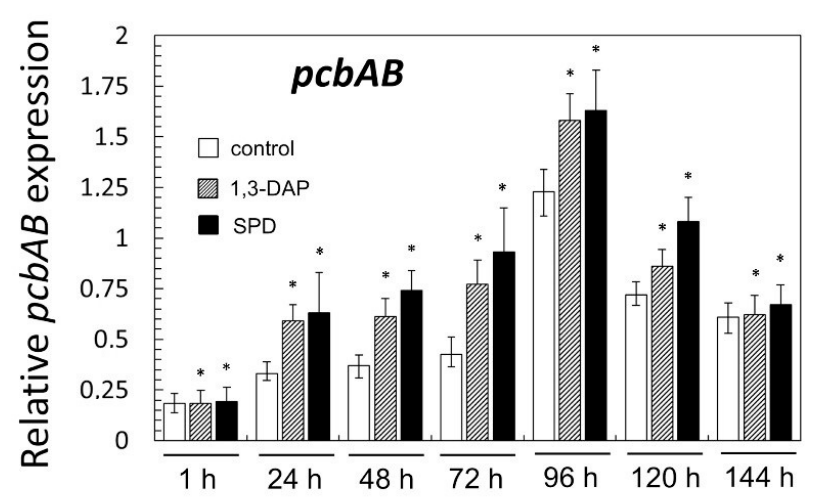

(a)

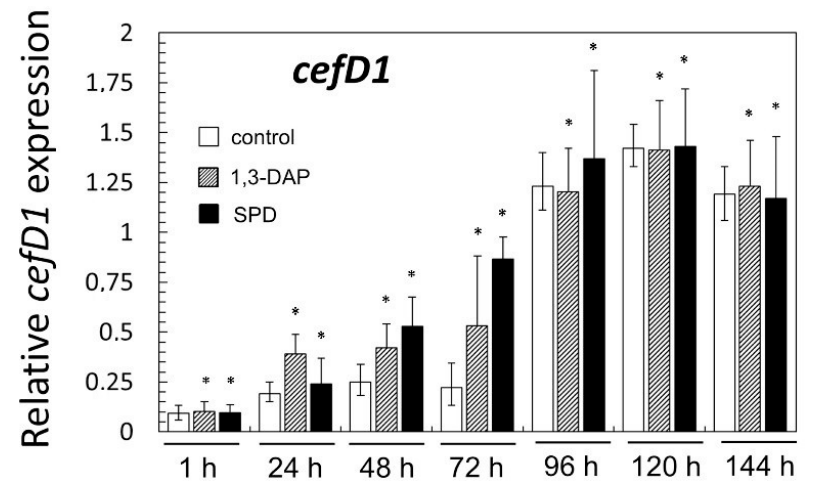

(c)

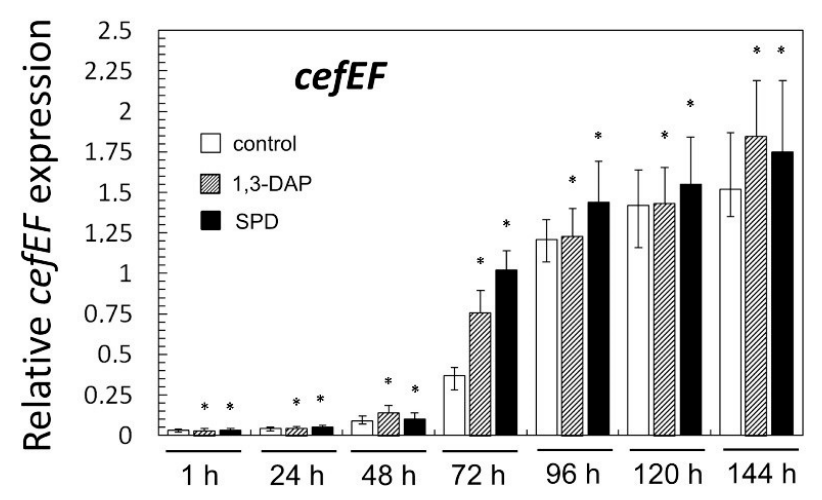

(e)

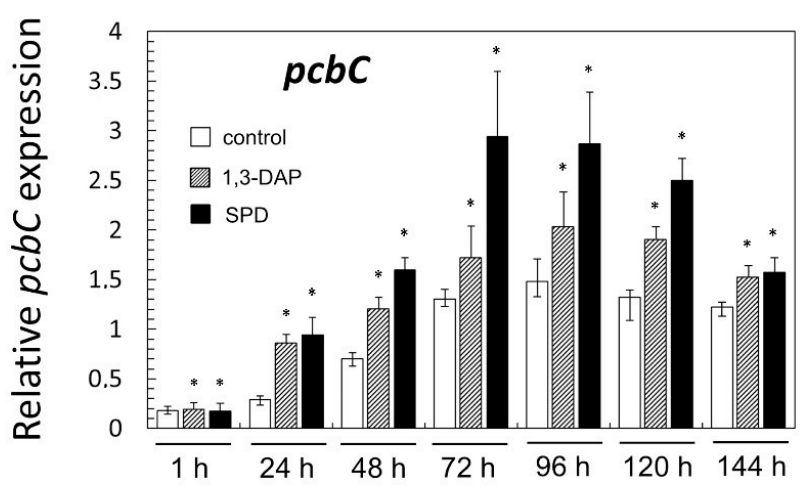

(b)

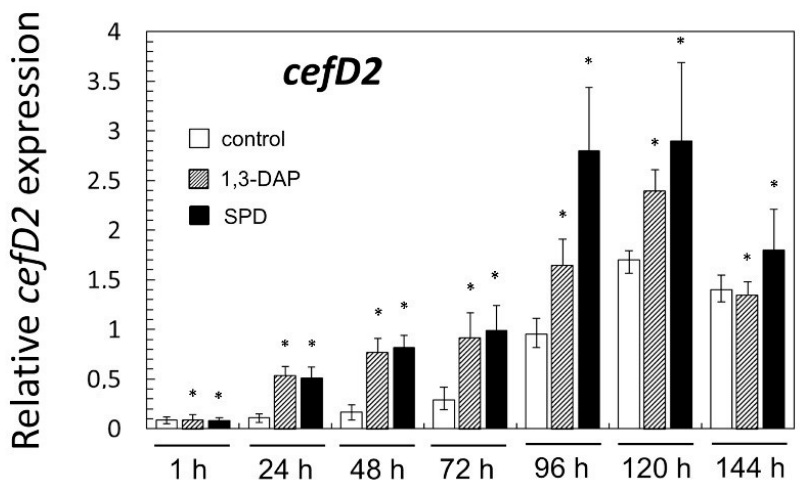

(d)

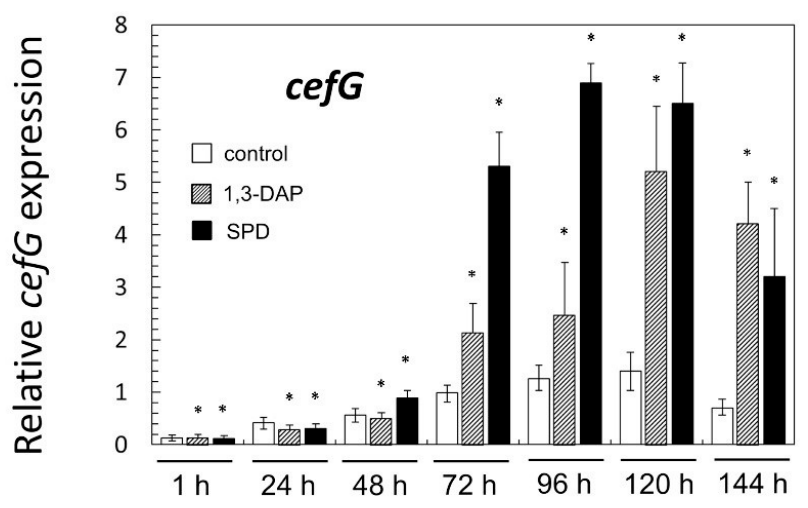

(f)

Figure 7. Expression dynamics of: (a) $p c b A B$; (b) $p c b C$; (c) cefD1; (d) cefD2; (e) cefEF; (f) cefG genes in A. chrysogenum HY strain after the addition $5 \mathrm{mM}$ 1,3-DAP or $5 \mathrm{mM}$ spermidine (SPD). After 1, 24, 48, 72, 96, 120, and $144 \mathrm{~h}$ of fermentation on complex $(\mathrm{CP})$ medium. Data are means $\pm \mathrm{SD}, n=3$. Statistical significance, ${ }^{*} p \leq 0.05$, as compared with the control (strain, cultivated on medium without PAs additions).

\section{Discussion}

SMs in filamentous fungi are synthesized in the idiophase, which replaces the first phase of development, the tropophase [48]. The addition of PAs on an agar medium stimulates, in the wild-type strain, the appearance of the characteristic yellow-cream coloration associated with the biosynthesis of the SM of sorbicillin a few days earlier (Figure 2). This effect of PAs on accelerating the functioning of the secondary metabolic pathway may be more universal. It has previously been shown that the addition of $5 \mathrm{mM}$ 1,3-DAP or $5 \mathrm{mM}$ spermidine enhances the yellow-green pigment coloration of Penicillium chrysogenum $54-1255$ by increasing the production of the yellow compound component chrysogenin [27]. Additionally, it was shown that PAs could stimulate an earlier production 
of the target $\mathrm{SM}$ in improved fungi strain during submerged fermentation. Thus, the addition of $5 \mathrm{mM}$ 1,3-DAP or $5 \mathrm{mM}$ SPS made it possible to obtain lovastatin during the fermentation of high-yielding $A$. terreus 3 days earlier than in the control [28]. Targeted knockout of the sor $A$ or $\operatorname{sor} B$ genes (encoding the central enzymes, polyketide synthases of sorbicilinoid BGC) in the A. chrysogenum wild-type strain results in a white phenotype, exactly the same as in $A$. chrysogenum HY [43]. It can be assumed that in A. chrysogenum HY, the biosynthesis of sorbicillin was disrupted; therefore, the yellow-cream color does not develop either during the idiophase period or under the influence of polyamines. This may be due to screening after random mutagenesis when mutants with disruption of the biosynthesis of alternative SM are also selected [49]. The inability of the improved strains to synthesize some alternative SM was shown at the molecular level and may be due to the release of additional resources for targeted biosynthesis [49]. Disruption of the biosynthesis of polyketide sorbicillin could lead to an additional increase in the production of cephalosporin $\mathrm{C}$ in $A$. chrysogenum $\mathrm{HY}$.

The addition of PAs also showed the stimulation of colonial germination, quantified by an increase in CFU/mL (Figure 3e). This is due to the fact that the improved producer is an extremely weakened strain, and even on a complete medium, not all colonies germinate. Thus, $\mathrm{OD}_{600}=0.5$ were $\sim 2.7 \times 10^{7} \mathrm{CFU} / \mathrm{mL}$ for the $A$. chrysogenum WT strain and $1.6 \times 10^{6} \mathrm{CFU} / \mathrm{mL}$ for the $A$. chrysogenum $\mathrm{HY}$ strain. Industrial strains with overproduction of SMs, obtained using classical strain improvement (CSI) programs, often contain unwanted side mutations and "bottlenecks" that negatively affect the fitness of the strain, resistance, productivity, and adaptation to harsh fermentation conditions [2,50,51]. It is possible that the introduction of exogenous PAs could complement or correct some of these negative effects. A similar stimulating effect on the germination of colonies after adding $5 \mathrm{mM}$ PAs to the agar culture medium was shown for a high-yielding Aspergillus terreus strain, a producer of lovastatin [28].

The addition of PAs on the agar medium also increased the viability of the HY strain in terms of colony size (Figure 3e). The heterogeneity in the size of the colonies was removed; small and medium colonies reached the size of large colonies for this strain. In addition, extremely weakened colonies germinated, which did not appear on the medium without polyamines (and they were also large in size). Due to this, the total number of colonies increases by about 3-5 times with the addition of $5 \mathrm{mM}$ PAs. The addition of spermidine further increased the colony size. Colonies that actively produce CPC are smaller than large nesting colonies that lose high activity [11]. In this regard, it was important to determine whether the increase in the viability of the HY strain upon the introduction of PAs is accompanied by a loss of high CPC activity. This was revealed in submerged fermentation, where we were able to find the conditions under which the addition of PA led to an increase in the production of the CPC of the HY strain (Figures 4 and 5).

The observed effect of the increase in the size and number of HY strain colonies upon the addition of PAs could not be scaled in the case of submerged fermentation. The addition of PAs did not lead to an increase in biomass compared to the control (Figure 5b). In addition, a slight decline, by 3-5\%, was observed in biomass production when cultivated with PAs in the later stages of fermentation. Cultivation after $144 \mathrm{~h}$, both with added PA and in the control, resulted in a sharp drop in biomass and the content of CPC. In another study, at the end of fermentation with PAs of the high-yielding strain A. terreus, the decrease in biomass was more significant and reached 10-15\% [28]. Additionally, a decrease in biomass occurred at the end of fermentation with PAs of the improved P. chrysogenum Wis 54-1255, by 3-5\% [27]. Possibly, the concentration of PAs that stimulate SM production in improved strains is toxic at the last stages of fermentation or leads to earlier aging.

In our work, for the A. chrysogenum $\mathrm{HY}$ strain, the conditions were optimized where the final yield of CPC was increased by $10-15 \%$ due to the introduction of PAs. Earlier, when working with $A$. chrysogenum HY, we could not obtain a CPC yield of more than $12,000 \mathrm{mg} / \mathrm{L}$ during fermentation in flasks. With the addition of 1,3-DAP, the yield of CPC increased to 13,100 mg/L; with the addition of SPD, it increased to 13,300 mg/L (Figure 5a). 
This is an important result that can be realized in practice. Earlier, for an improved producer of $A$. terreus, the addition of exogenous PAs increased the production of lovastatin by $20-45 \%$, but this increase was on day 8 (out of 11) of fermentation [28]. Further, the production of lovastatin decreased; the practical significance, in this case, was associated with obtaining the same amount of lovastatin as in the control, but 3 days faster, thanks to the addition of PAs.

It is also important that the addition of PAs has a balanced effect on beta-lactam metabolism in A. chrysogenum HY. The total increase in the admixture products of betalactam metabolism does not exceed the increase in the production of CPC (Figure 6). Due to this, the percentage of admixtures after fermentation of $A$. chrysogenum HY with PAs remains at the control level, $10-15 \%$.

This shows that PAs effectively influence the entire biosynthetic pathway of betalactams in A. chrysogenum HY; no limiting stage arises, leading to an increased content of the intermediate biosynthesis product. Thus, in the previous work with this strain, the expression of an additional copy of the cefT gene (encoding the beta-lactam transporter) led to an increase in intermediate biosynthesis products (IPN, DAOC, and DAC) and a decrease in the yield of CPC [15]. In another study, an increase in the activity of $\mathrm{H}^{+}$ATPase plasma membrane (PMA) in recombinant $A$. chrysogenum HY strains correlated with an increase in DAC and a decrease in CPC production as a result of ATP deficiency [2]. For the last stage of beta-lactam biosynthesis, cytoplasmic acetyl-coenzyme $\mathrm{A}$ is required as a substrate; its synthesis consumes ATP. PMA is the main enzyme that consumes cell ATP; in recombinant clones with increased PMA activity, the ATP content sharply decreases, disrupting high-energy beta-lactam biosynthesis, especially at the last stage [2]. The fact that an increase in CPC production with the addition of PAs does not lead to an increase in the percentage of impurities is important, from a technological point of view, when isolating and purifying the substance (Figure 6).

Earlier, we showed that in an A. chrysogenum HY strain, the "early" and "late" genes of beta-lactam BGCs are upregulated 5-300 times compared to the A. chrysogenum WT strain [13]. In the current study, it was shown that the introduction of PAs leads to additional upregulation of all six genes for the biosynthesis of beta-lactams $(p c b A B, p c b C$, $c e f D 1, \operatorname{cefD2}$, cefEF, and cefG) (Figure 7). Since we previously studied the expression of these genes only after 0 (at the time of inoculum from DP to CP medium), 48, and $120 \mathrm{~h}$, the study of additional time points allowed us to more clearly trace the dynamics of their expression [13]. It was possible to trace exactly when the action of polyamines at the molecular level is turned on. For "early" genes, this impact was in the period of 24-120 h (Figure 7a-d), for "late" genes-in the period 72-144 h (Figure 7e,f). Detection of cefG upregulation is especially significant since the final stage of the CPC biosynthetic pathway is rate-limiting and estimated as a "bottleneck" for CPC biosynthesis [2]. Several improved A. chrysogenum strains produce significant amounts of DAC byproduct due to insufficient activity of the CefG enzyme, which significantly reduces the yield of the target metabolite, CPC [52]. The fact that the increase in the production of CPC under the influence of PAs in the HY strain is not accompanied by a significant increase in byproducts, especially DAC, can be partly explained by the increased expression of $c e f G$ under the influence of PAs (Figures 6 and $7 \mathrm{f}$ ).

\section{Materials and Methods}

\subsection{Materials}

1,3-diaminopropane (1,3-DAP) and spermidine (Spd) were obtained from MP Biomedicals.

\subsection{Strains of Microorganisms}

A. chrysogenum ATCC 11550 (WT, wild type Brotzu isolate, [53]) and A. chrysogenum RNCM 408D (HY, high-yielding CPC producer, derived from the WT, [11]) were used in this work. 


\subsection{Cultivation of A. chrysogenum Strains on Agarized Media with PAs}

A. chrysogenum strains were cultivated on agarized complex (CPA) medium $(40 \mathrm{~g} / \mathrm{L}$ maltose, $10 \mathrm{~g} / \mathrm{L}$ peptone, $20 \mathrm{~g} / \mathrm{L}$ malt extract, $25 \mathrm{~g} / \mathrm{L}$ agar, $\mathrm{pH}$ 7.0-7.4), or agarized Czapek-Dox (CDA) medium (30 g/L sucrose, $2 \mathrm{~g} / \mathrm{L} \mathrm{NaNO}, 1 \mathrm{~g} / \mathrm{L} \mathrm{K}_{2} \mathrm{HPO}_{4}, 0.5 \mathrm{~g} / \mathrm{L}$ $\mathrm{MgSO}_{4} \cdot 7 \mathrm{H}_{2} \mathrm{O}, 0.5 \mathrm{~g} / \mathrm{L} \mathrm{KCl}, 0.01 \mathrm{~g} / \mathrm{L} \mathrm{FeSO}_{4} \cdot 7 \mathrm{H}_{2} \mathrm{O}, 25 \mathrm{~g} / \mathrm{L}$ agar, $\mathrm{pH}$ 7.0-7.4), or agarized LPE medium (10 g/L glucose, $20 \mathrm{~g} / \mathrm{L}$ yeast extract, $15 \mathrm{~g} / \mathrm{L} \mathrm{NaCl}, 10 \mathrm{~g} / \mathrm{L} \mathrm{CaCl}_{2}, 25 \mathrm{~g} / \mathrm{L}$ agar, $\mathrm{pH}$ 6.8). CPA medium was supplemented with 1,3-DAP or SPD in the concentration range $0.1-10 \mathrm{mM}$ or used without additions (control).

To determine the effect of PAs on the growth and morphology of A. chrysogenum colonies, the serial dilution method was used. A. chrysogenum cells were collected from CPA slants and diluted with $0.9 \% \mathrm{NaCl}$ up to $\mathrm{OD}_{600}=0.5$ (basic concentration), followed by 6-7 serial tenfold dilutions with the same solvent. Then, $50 \mu \mathrm{L}$ of cell suspension was inoculated onto Petri dishes (with CPA medium prepared with or without the addition of $0.1-10 \mathrm{mM} 1,3$-DAP or SPD), incubated at $28^{\circ} \mathrm{C}$ for 10-15 days for A. chrysogenum WT cells or 18-25 days for A. chrysogenum HY. Colonies on a medium with PAs were compared with colonies in control, in dilutions with 5-500 colonies. The effect of the PAs' addition on the number of germinating colonies was evaluated as ratio of $\mathrm{CFU} / \mathrm{mL}$ (colony forming units) of cell counts after incubation with PAs, compared with control counts (on CPA media without any additions), i.e., normalized to control. For reference, the average control counts were approximately $2.7 \times 10^{7} \mathrm{CFU} / \mathrm{mL}$ for A. chrysogenum WT strain and $1.6 \times 10^{6} \mathrm{CFU} / \mathrm{mL}$ for $A$. chrysogenum $\mathrm{HY}$ strain.

The effect of PAs on the colony size was calculated as the ratio of the average diameter of all colonies after inoculation on CPA with PAs compared to control's average diameter of colonies (on CPA media without any additions that were grown from the inoculum of the same dilution). The counting of the number and size of colonies was carried out after 5 days of incubation for the WT strain and after 12 days of incubation for the HY strain. Data represent triplicates from four separate experiments, with the mean and SEM displayed.

\subsection{Submerged Fermentation of A. chrysogenum HY Strain with Exogenous PAs}

A. chrysogenum HY strain was routinely cultured on CPA slants. To prepare the strain for antibiotic production, it was inoculated from CPA on LPE slants, incubated 10 days at $28{ }^{\circ} \mathrm{C}$; the whole content collected from agar with $5 \mathrm{~mL} 0.9 \% \mathrm{NaCl}$, transferred to $25 \mathrm{~mL}$ of the defined (DP) medium $(28 \mathrm{~g} / \mathrm{L}$ yeast extract, $28 \mathrm{~g} / \mathrm{L}$ malt extract, $10 \mathrm{~g} / \mathrm{L}$ peptone, $4 \mathrm{~g} / \mathrm{L}$ chalk, $20 \mathrm{~g} / \mathrm{L}$ soybean oil, $\mathrm{pH}$ 7.2) in $250 \mathrm{~mL}$ Erlenmeyer flasks, and incubated on a rotary shaker at $220-240 \mathrm{rpm}$ at $28^{\circ} \mathrm{C}$. After $48 \mathrm{~h}$ of growth, $20 \mathrm{~mL}$ of culture was inoculated in $35 \mathrm{~mL}$ of complex (CP) medium (105 g/L corn extract, $60 \mathrm{~g} / \mathrm{L}$ corn dextrin, $20 \mathrm{~g} / \mathrm{L}$ corn starch, $3 \mathrm{~g} / \mathrm{L} \mathrm{KH}_{2} \mathrm{PO}_{4}, 5 \mathrm{~g} / \mathrm{L}$ glucose, $3.5 \mathrm{~g} / \mathrm{L} \mathrm{MgSO} 4,14 \mathrm{~g} / \mathrm{L}\left(\mathrm{NH}_{4}\right)_{2} \mathrm{SO}_{4}, 11 \mathrm{~g} / \mathrm{L}$ chalk, $20 \mathrm{~g} / \mathrm{L}$ soybean oil; supplemented with microelements: $18 \mathrm{mg} / \mathrm{L} \mathrm{CuSO}_{4} \cdot 5 \mathrm{H}_{2} \mathrm{O}, 150 \mathrm{mg} / \mathrm{L}$ $\mathrm{ZnSO}_{4} \cdot 7 \mathrm{H}_{2} \mathrm{O}, 30 \mathrm{mg} / \mathrm{L} \mathrm{MnSO}{ }_{4} \cdot 7 \mathrm{H}_{2} \mathrm{O}, 70 \mathrm{mg} / \mathrm{L} \mathrm{FeSO}_{4} \cdot 7 \mathrm{H}_{2} \mathrm{O}$, pH 6.2-6.4). Fermentation was performed in $750 \mathrm{~mL}$ Erlenmeyer flasks for $144 \mathrm{~h}(240 \mathrm{rpm})$ at $28^{\circ} \mathrm{C}$ for the first $24 \mathrm{~h}$ and at $24{ }^{\circ} \mathrm{C}$ for the rest of the process. A total of $0.5-5 \mathrm{mM} 1,3-\mathrm{DAP}$ or SPD was added at various stages of the preparation of HY strain for fermentation and the fermentation itself: (i) preliminary cultivation on LPE slants; (ii) two consecutive passages on slant agar, each time with the addition of PAs; (iii) at the time of inoculum from LPE slants to DP medium; (iv) at the time of inoculum from DP medium to CP medium; (v) after $24 \mathrm{~h}$ of cultivation on CP medium; (vi) after $72 \mathrm{~h}$ of cultivation on $\mathrm{CP}$ medium.

\subsection{Determination of Dry Biomass}

Aliquots $(2 \mathrm{~mL})$, which included medium and cells, were taken after $24 \mathrm{~h}, 48 \mathrm{~h}$, $72 \mathrm{~h}, 96 \mathrm{~h}, 120 \mathrm{~h}$, and $144 \mathrm{~h}$ of growth, centrifuged in a $15 \mathrm{~mL}$ falcon at $4800 \times \mathrm{g}$, washed three times with 10 volumes of $\mathrm{H}_{2} \mathrm{O}$ and placed in a thermostat at $80^{\circ} \mathrm{C}$. Drying was carried out for 48-72 h until a constant weight was established. Dry biomass was determined by the difference between the weight of dried cells and empty falcon. Data represent triplicates from four separate experiments, with the mean and SEM displayed. 


\subsection{HPLC Analysis of Beta-Lactams}

To determine the yield of cephalosporin $C$ and byproducts of the biosynthesis of beta-lactams, aliquots of the culture fluid were taken after $24 \mathrm{~h}, 48 \mathrm{~h}, 72 \mathrm{~h}, 96 \mathrm{~h}, 120 \mathrm{~h}$, and $144 \mathrm{~h}$ of growth. The concentration beta-lactams in the culture broth was determined in the mobile phase $\mathrm{CTAB}$ /acetonitrile/phosphoric acid/water on a chromatographic column YMC-Pack ODS-A (YMC CO., Kyoto, Japan) with a particle diameter of $5 \mu \mathrm{m}$ at a flow rate of the mobile phase of $1.0 \mathrm{~mL} / \mathrm{min}$, and a detection wavelength of $254 \mathrm{~nm}$. Data represent triplicates from four separate experiments, with the mean and SEM displayed.

\subsection{Preparation of Total RNA and $c D N A$ Synthesis and qPCR Analysis}

Cell samples for total RNA extraction were taken at $1 \mathrm{~h}, 24 \mathrm{~h}, 48 \mathrm{~h}, 72 \mathrm{~h}, 96 \mathrm{~h}, 120 \mathrm{~h}$, and $144 \mathrm{~h}$ of growth, filtered, washed with PBS, lyophilized, and stored at $-80^{\circ} \mathrm{C}$. The total RNA preparation and cDNA synthesis were carried out as described previously [13,15]. qPCR reactions were performed with previously developed pairs of primers for analysis of gene expression of CPC biosynthesis ( $p c b A B, p c b C, c e f D 1, c e f D 2, c e f E F$, and cefG) (Table 1) [2,13]. Reactions and processing of the results were carried out in accordance with the protocol [13]. To normalize the data of expression levels, we used previously designed pair of primers for the housekeeping $\gamma$-actin gene [15]. Data represent triplicates from four separate experiments, with the mean and SEM displayed.

Table 1. Primers used for RT-PCR analysis.

\begin{tabular}{|c|c|c|c|c|}
\hline Primer & Gene & Product, Function & Oligonucleotide (Sequence $5 \rightarrow 3$ ) & Source Sequence \\
\hline $\begin{array}{l}\text { actq1 } \\
\text { actq2 }\end{array}$ & act1 & $\gamma$-actin, a major component of the cytoskeleton & $\begin{array}{l}\text { CCGGTTTCGCCGGTGATGATGCT } \\
\text { TGCTCAATGGGGTAGCGCAG }\end{array}$ & JN836733.1 [15] \\
\hline $\begin{array}{l}\text { pcbABq3 } \\
\text { pcbABq4 }\end{array}$ & $p c b A B$ & $\begin{array}{l}\delta \text {-(L- } \alpha \text {-aminoadipyl)-L-systeinyl-D- } \\
\text { valine synthetase }\end{array}$ & $\begin{array}{l}\text { AGGCATCGTCAGGTTGGCCG } \\
\text { CCGGAGGGGCCATACCACAT }\end{array}$ & E05192.1 [13] \\
\hline $\begin{array}{l}\text { pcbCq1 } \\
\text { pcbCq2 }\end{array}$ & $p c b C$ & isopenicillin $\mathrm{N}$-synthase & $\begin{array}{l}\text { CTAGGTCGCGACGAGGACTTCT } \\
\text { CACGTCGGACTGGTACAACACC }\end{array}$ & M33522.1 [13] \\
\hline $\begin{array}{l}\text { cefD1q1 } \\
\text { cefD1q2 }\end{array}$ & cefD1 & $\begin{array}{l}\text { isopenicillin N-CoA } \\
\text { synthetase }\end{array}$ & $\begin{array}{l}\text { CCCCGGTGAGGAAGATGCGT } \\
\text { TCGATCTCCGCCTTGGACGC }\end{array}$ & AI507632 2 [13] \\
\hline $\begin{array}{l}\text { cefD2q1 } \\
\text { cefD2q2 }\end{array}$ & cefD2 & isopenicillin $\mathrm{N}-\mathrm{Co} A$ epimerase & $\begin{array}{l}\text { ACAGGATGGAGAGGAGCACCTTG } \\
\text { TCGTAGAGCTCGCGGGGCTA }\end{array}$ & \\
\hline $\begin{array}{l}\text { cefEFq3 } \\
\text { cefEFq4 }\end{array}$ & cefEF & $\begin{array}{l}\text { deacetoxycephalosporin C } \\
\text { synthetase/hydroxylase }\end{array}$ & $\begin{array}{l}\text { GTCGAGTGCGATCCCCTCCT } \\
\text { CGAATTCTCCGTCCACCTCG }\end{array}$ & AJ404737.1 [2] \\
\hline $\begin{array}{l}\text { cefGq3 } \\
\text { cefGq4 }\end{array}$ & $c e f G$ & $\begin{array}{l}\text { deacetylcephalosporin-C } \\
\text { acetyltransferase }\end{array}$ & $\begin{array}{l}\text { ATCTCAGTCTCCGAAGCGTCCTGG } \\
\text { CGAGGATTTGTGACCGACATAAGTGG }\end{array}$ & M91649.1 [2] \\
\hline
\end{tabular}

\subsection{Statistical Analysis}

The experimental data were expressed as mean value \pm standard error of mean (SEM) calculated from three parallel experiments. The statistical analysis was performed by one-way analysis of variance (ANOVA) using Microsoft Excel. Differences described by $p \leq 0.05$ were considered significant.

\section{Conclusions}

In our work, we showed that the introduction of exogenous polyamines could additionally increase the production of cephalosporin C in a high-yielding Acremonium chrysogenum strain, by 10-15\%. This was accompanied by an upregulation of both "early" and "late" genes from the biosynthetic clusters of beta-lactams, especially cefG, which encodes a key enzyme of the final biosynthesis stage that converts deacetylcephalosporin $\mathrm{C}$ to cephalosporin C. Since it was previously shown that exogenous polyamines could increase the production of other improved fungi producers, in particular, the production of penicillin $G$ and lovastatin, our results may reflect a certain general trend that can be implemented in the cultivation of industrial fungi strains. 
Author Contributions: Conceptualization, A.A.Z. and M.A.E.; methodology, A.A.Z.; software, A.A.Z.; validation, A.A.Z. and M.A.E.; formal analysis, A.A.Z.; investigation, A.A.Z.; resources, A.A.Z. and M.A.E.; data curation, A.A.Z. and M.A.E.; writing-original draft preparation, A.A.Z.; writing-review and editing A.A.Z.; visualization, A.A.Z.; supervision, A.A.Z. and M.A.E.; project administration, A.A.Z. and M.A.E.; funding acquisition, A.A.Z. All authors have read and agreed to the published version of the manuscript.

Funding: This research was partially funded by Russian Foundation for Basic Research (grant number 19-04-01173).

Institutional Review Board Statement: Not applicable.

Informed Consent Statement: Not applicable.

Data Availability Statement: The data presented in this study is contained within the article.

Conflicts of Interest: The authors declare no conflict of interests.

Sample Availability: Samples of the compounds are not available from the authors.

\section{References}

1. Singh, A.K.; Rana, H.K.; Pandey, A.K. Fungal-Derived Natural Product: Synthesis, Function, and Applications; Springer: New York, NY, US, 2019; pp. 229-248. [CrossRef]

2. Zhgun, A.; Dumina, M.; Valiakhmetov, A.; Eldarov, M. The critical role of plasma membrane $\mathrm{H}^{+}$-ATPase activity in cephalosporin C biosynthesis of Acremonium chrysogenum. PLoS ONE 2020, 15, e0238452. [CrossRef]

3. Zhgun, A.A.; Dumina, M.V.; Voinova, T.M.; Dzhavakhiya, V.V.; Eldarov, M.A. Role of acetyl-CoA Synthetase and LovE Regulator Protein of Polyketide Biosynthesis in Lovastatin Production by Wild-Type and Overproducing Aspergillus terreus Strains. Appl. Biochem. Microbiol. 2018, 54, 188-197. [CrossRef]

4. Domratcheva, A.G.; Zhgun, A.A.; Novak, N.V.; Dzhavakhiya, V.V. The Influence of Chemical Mutagenesis on the Properties of the Cyclosporine a High-Producer Strain Tolypocladium inflatum VKM F-3630D. Appl. Biochem. Microbiol. 2018, 54, 53-57. [CrossRef]

5. Cephalosporin Market Size, Share, Growth, Trends and Forecast 2021-2026. Available online: https:/ /www.imarcgroup.com/ cephalosporin-market (accessed on 8 October 2021).

6. Rodriguez-Herrera, R.; Puc, L.E.C.; Sobrevilla, J.M.V.; Luque, D.; Cardona-Felix, C.S.; Aguilar-González, C.N.; Flores-Gallegos, A.C. Enzymes in the Pharmaceutical Industry for $\beta$-Lactam Antibiotic Production. In Enzymes in Food Biotechnology. Production, Applications, and Future Prospects; Kuddus, M., Ed.; Academic Press: Cambridge, MA, USA, 2019; pp. 627-643. [CrossRef]

7. Toai, B.; Preuss, C.V. Cephalosporins; StatPearls: Treasure Island, FL, USA, 2021.

8. Elander, R.P. Industrial production of $\beta$-lactam antibiotics. Appl. Microbiol. Biotechnol. 2003, 61, 385-392. [CrossRef] [PubMed]

9. Liu, Y.; Gong, G.; Xie, L.; Yuan, N.; Zhu, C.; Zhu, B.; Hu, Y. Improvement of Cephalosporin C Production by Recombinant DNA Integration in Acremonium chrysogenum. Mol. Biotechnol. 2010, 44, 101-109. [CrossRef] [PubMed]

10. Martín, J.F.; Ullán, R.V.; García-Estrada, C. Regulation and compartmentalization of $\beta$-lactam biosynthesis. Microb. Biotechnol. 2010, 3, 285-299. [CrossRef] [PubMed]

11. Bartoshevich, Y.; Novak, M.; Domratcheva, A.; Skrybin, K. Method of Cephalosporin C Biosynthesis by Using New Acremonium chrysogenum Strain RNCM NO F-4081D. Patent RU 2426793, 20 August 2011.

12. Dumina, M.V.; Zhgun, A.A.; Domracheva, A.G.; Novak, M.I.; El'darov, M.A. Chromosomal polymorphism of Acremonium chrysogenum strains producing cephalosporin C. Russ. J. Genet. 2012, 48, 778-784. [CrossRef]

13. Dumina, M.V.; Zhgun, A.A.; Novak, M.I.; Domratcheva, A.G.; Petukhov, D.V.; Dzhavakhiya, V.V.; Eldarov, M.A.; Bartoshevitch, I.E. Comparative gene expression profiling reveals key changes in expression levels of cephalosporin C biosynthesis and transport genes between low and high-producing strains of Acremonium chrysogenum. World J. Microbiol. Biotechnol. 2014, 30, $2933-2941$. [CrossRef]

14. Zhgun, A.A.; Ivanova, M.A.; Domracheva, A.G.; Novak, M.I.; Elidarov, M.A.; Skryabin, K.G.; Bartoshevich, Y.E. Genetic transformation of the mycelium fungi Acremonium chrysogenum. Appl. Biochem. Microbiol. 2008, 44, 600-607. [CrossRef]

15. Dumina, M.V.; Zhgun, A.A.; Kerpichnikov, I.V.; Domracheva, A.G.; Novak, M.I.; Valiachmetov, A.Y.; Knorre, D.A.; Severin, F.F.; Eldarov, M.A.; Bartoshevich, Y.E. Functional analysis of MFS protein CefT involved in the transport of beta-lactam antibiotics in Acremonium chrysogenum and Saccharomyces cerevisiae. Appl. Biochem. Microbiol. 2013, 49, 368-377. [CrossRef]

16. Valiakhmetov, A.Y.; Trilisenko, L.V.; Vagabov, V.M.; Bartoshevich, Y.E.; Kulaev, I.S.; Novak, M.I.; Domracheva, A.G.; El'darov, M.A.; Skryabin, K.G. The concentration dynamics of inorganic polyphosphates during the cephalosporin C synthesis by Acremonium chrysogenum. Appl. Biochem. Microbiol. 2010, 46, 184-190. [CrossRef]

17. Kalebina, T.S.; Selyakh, I.O.; Gorkovskii, A.A.; Bezsonov, E.E.; El'darov, M.A.; Novak, M.I.; Domracheva, A.G.; Bartoshevich, Y.E. Structure peculiarities of cell walls of Acremonium chrysogenum-an autotroph of cephalosporin C. Appl. Biochem. Microbiol. 2010, 46, 614-619. [CrossRef] 
18. Hyvönen, M.T.; Keinänen, T.A.; Nuraeva, G.K.; Yanvarev, D.V.; Khomutov, M.; Khurs, E.N.; Kochetkov, S.N.; Vepsäläinen, J.; Zhgun, A.A.; Khomutov, A.R. Hydroxylamine analogue of agmatine: Magic bullet for arginine decarboxylase. Biomolecules 2020, 10, 406. [CrossRef] [PubMed]

19. Valdés-Santiago, L.; Ruiz-Herrera, J. Stress and polyamine metabolism in fungi. Front. Chem. 2013, 1, 42. [CrossRef] [PubMed]

20. Ruiz-Herrera, J. Polyamines, DNA methylation, and fungal differentiation. Crit. Rev. Microbiol. 1994, 20, 143-150. [CrossRef]

21. Guevara-Olvera, L.; Calvo-Mendez, C.; Ruiz-Herrera, J. The role of polyamine metabolism in dimorphism of Yarrowia lipolytica. J. Gen. Microbiol. 1993, 139, 485-493. [CrossRef]

22. Dorighetto Cogo, A.J.; Dutra Ferreira, K.d.R.; Okorokov, L.A.; Ramos, A.C.; Façanha, A.R.; Okorokova-Façanha, A.L. Spermine modulates fungal morphogenesis and activates plasma membrane $\mathrm{H}^{+}$-ATPase during yeast to hyphae transition. Biol. Open 2018, 7, bio029660. [CrossRef]

23. Valdés-Santiago, L.; Cervantes-Chávez, J.A.; León-Ramírez, C.G.; Ruiz-Herrera, J. Polyamine Metabolism in Fungi with Emphasis on Phytopathogenic Species. J. Amino Acids 2012, 2012, 837932. [CrossRef]

24. Nambeesan, S.; AbuQamar, S.; Laluk, K.; Mattoo, A.K.; Mickelbart, M.V.; Ferruzzi, M.G.; Mengiste, T.; Handa, A.K. Polyamines Attenuate Ethylene-Mediated Defense Responses to Abrogate Resistance to Botrytis cinerea in Tomato. Plant Physiol. 2012, 158, 1034. [CrossRef]

25. Rocha, R.O.; Wilson, R.A. Essential, deadly, enigmatic: Polyamine metabolism and roles in fungal cells. Fungal Biol. Rev. 2019, 33, 47-57. [CrossRef]

26. Valdés-Santiago, L.; Ruiz-Herrera, J. Polyamines in Fungi: Their Distribution, Metabolism, and Role in Cell Differentiation and Morphogenesis. Polyam. Fungi Their Distrib. Metab. Role Cell Differ. Morphog. 2015, 17, 1-186. [CrossRef]

27. Martín, J.; García-Estrada, C.; Kosalková, K.; Ullán, R.V.; Albillos, S.M.; Martín, J.-F. The inducers 1,3-diaminopropane and spermidine produce a drastic increase in the expression of the penicillin biosynthetic genes for prolonged time, mediated by the LaeA regulator. Fungal Genet. Biol. 2012, 49, 1004-1013. [CrossRef]

28. Zhgun, A.A.; Nuraeva, G.K.; Dumina, M.V.; Voinova, T.M.; Dzhavakhiya, V.V.; Eldarov, M.A. 1,3-Diaminopropane and Spermidine Upregulate Lovastatin Production and Expression of Lovastatin Biosynthetic Genes in Aspergillus terreus via LaeA Regulation. Appl. Biochem. Microbiol. 2019, 55, 243-254. [CrossRef]

29. Martín, J.F. Key role of LaeA and velvet complex proteins on expression of $\beta$-lactam and PR-toxin genes in Penicillium chrysogenum: Cross-talk regulation of secondary metabolite pathways. J. Ind. Microbiol. Biotechnol. 2017, 44, 525-535. [CrossRef]

30. Zhgun, A.A.; Nuraeva, G.K.; Eldarov, M.A. The Role of LaeA and LovE Regulators in Lovastatin Biosynthesis with Exogenous Polyamines in Aspergillus terreus. Appl. Biochem. Microbiol. 2019, 55, 639-648. [CrossRef]

31. Strauss, J.; Reyes-Dominguez, Y. Regulation of secondary metabolism by chromatin structure and epigenetic codes. Fungal Genet. Biol. 2011, 48, 62-69. [CrossRef]

32. Gerke, J.; Braus, G.H. Manipulation of fungal development as source of novel secondary metabolites for biotechnology. Appl. Microbiol. Biotechnol. 2014, 98, 8443. [CrossRef] [PubMed]

33. Ahmed, Y.; Gerke, J.; Park, H.; Bayram, Ö.; Neumann, P.; Ni, M.; Dickmanns, A.; Kim, S.; Yu, J.; Braus, G.; et al. The velvet family of fungal regulators contains a DNA-binding domain structurally similar to NF-kB. PLoS Biol. 2013, 11, e1001750. [CrossRef]

34. Bayram, Ö.S.; Bayram, Ö.; Valerius, O.; Park, H.S.; Irniger, S.; Gerke, J.; Ni, M.; Han, K.-H.; Yu, J.-H.; Braus, G.H. LaeA Control of Velvet Family Regulatory Proteins for Light-Dependent Development and Fungal Cell-Type Specificity. PLoS Genet. 2010, 6, e1001226. [CrossRef]

35. Calvo, A.M.; Lohmar, J.M.; Ibarra, B.; Satterlee, T. Velvet Regulation of Fungal Development. In Growth, Differentiation and Sexuality; Wendland, J., Ed.; Springer: New York, NY, USA, 2016; pp. 475-497. [CrossRef]

36. Wang, R.; Leng, Y.; Shrestha, S.; Zhong, S. Coordinated and independent functions of velvet-complex genes in fungal development and virulence of the fungal cereal pathogen Cochliobolus sativus. Fungal Biol. 2016, 120, 948-960. [CrossRef] [PubMed]

37. Sarikaya-Bayram, Ö.; Palmer, J.M.; Keller, N.; Braus, G.H.; Bayram, Ö. One Juliet and four Romeos: VeA and its methyltransferases. Front. Microbiol. 2015, 6, 1. [CrossRef] [PubMed]

38. Lind, A.L.; Smith, T.D.; Saterlee, T.; Calvo, A.M.; Rokas, A. Regulation of secondary metabolism by the velvet complex is temperature-responsive in aspergillus. G3 Genes Genomes Genet. 2016, 6, 4023-4033. [CrossRef]

39. Bayram, Ö.S.; Dettmann, A.; Karahoda, B.; Moloney, N.M.; Ormsby, T.; McGowan, J.; Cea-Sánchez, S.; Miralles-Durán, A.; Brancini, G.T.P.; Luque, E.M.; et al. Control of Development, Secondary Metabolism and Light-Dependent Carotenoid Biosynthesis by the Velvet Complex of Neurospora crassa. Genetics 2019, 212, 691-710. [CrossRef]

40. Calvo, A.M.; Cary, J.W. Association of fungal secondary metabolism and sclerotial biology. Front. Microbiol. 2015, 6, 62. [CrossRef] [PubMed]

41. Collemare, J.; Seidl, M.F. Chromatin-dependent regulation of secondary metabolite biosynthesis in fungi: Is the picture complete? FEMS Microbiol. Rev. 2019, 43, 591-607. [CrossRef] [PubMed]

42. Keller, N.P. Fungal secondary metabolism: Regulation, function and drug discovery. Nat. Rev. Microbiol. 2019, 17, 167-180. [CrossRef] [PubMed]

43. Chen, G.; Chu, J. Characterization of Two Polyketide Synthases Involved in Sorbicillinoid Biosynthesis by Acremonium chrysogenum Using the CRISPR/Cas9 System. Appl. Biochem. Biotechnol. 2019, 188, 1134-1144. [CrossRef] 
44. Zhgun, A.; Avdanina, D.; Shumikhin, K.; Simonenko, N.; Lyubavskaya, E.; Volkov, I.; Ivanov, V. Detection of potential biodeterioration risks for tempera painting in 16th century exhibits from State Tretyakov Gallery. PLoS ONE 2020, 15, e0230591. [CrossRef]

45. Barrios-González, J.; Baños, J.G.; Covarrubias, A.A.; Garay-Arroyo, A. Lovastatin biosynthetic genes of Aspergillus terreus are expressed differentially in solid-state and in liquid submerged fermentation. Appl. Microbiol. Biotechnol. 2008, 79, 179-186. [CrossRef] [PubMed]

46. Miranda, R.U.; Gómez-Quiroz, L.E.; Mejía, A.; Barrios-González, J. Oxidative state in idiophase links reactive oxygen species (ROS) and lovastatin biosynthesis: Differences and similarities in submerged- and solid-state fermentations. Fungal Biol. 2013, 117, 85-93. [CrossRef] [PubMed]

47. Miranda, R.U.; Gómez-Quiroz, L.E.; Mendoza, M.; Pérez-Sánchez, A.; Fierro, F.; Barrios-González, J. Reactive oxygen species regulate lovastatin biosynthesis in Aspergillus terreus during submerged and solid-state fermentations. Fungal Biol. 2014, 118, 979-989. [CrossRef] [PubMed]

48. Demain, A.L. Regulation of secondary metabolism in fungi. Pure Appl. Chem. 1986, 58, 219-226. [CrossRef]

49. Terfehr, D.; Dahlmann, T.A.; Kück, U. Transcriptome analysis of the two unrelated fungal $\beta$-lactam producers Acremonium chrysogenum and Penicillium chrysogenum: Velvet-regulated genes are major targets during conventional strain improvement programs. BMC Genom. 2017, 18, 272. [CrossRef] [PubMed]

50. Salo, O.V.; Ries, M.; Medema, M.H.; Lankhorst, P.P.; Vreeken, R.J.; Bovenberg, R.A.L.; Driessen, A.J.M. Genomic mutational analysis of the impact of the classical strain improvement program on $\beta$-lactam producing Penicillium chrysogenum. BMC Genom. 2015, 16, 937. [CrossRef]

51. Zhgun, A.A.; Nuraeva, G.K.; Volkov, I.A. High-yielding lovastatin producer aspergillus terreus shows increased resistance to inhibitors of polyamine biosynthesis. Appl. Sci. 2020, 10, 8290. [CrossRef]

52. Gutiérrez, S.; Velasco, J.; Marcos, A.T.; Fernández, F.J.; Fierro, F.; Barredo, J.L.; Díez, B.; Martín, J.F. Expression of the the cefG gene is limiting for cephalosporin biosynthesis in Acremonium chrysogenum. Appl. Microbiol. Biotechnol. 1997, 48, 606-614. [CrossRef] [PubMed]

53. Newton, G.G.; Abraham, E.P. Isolation of cephalosporin C, a penicillin-like antibiotic containing D-alpha-aminoadipic acid. Biochem. J. 1956, 62, 651-658. [CrossRef] 